\title{
Effects of Periosteal Elevation Before Lateral Osteotomy in Rhinoplasty: A Meta-Analysis of Randomized Controlled Trials
}

\author{
Ji-Sun Kim (iD · Sun Hong Kim (iD · Hyesook Lee (D) · Byung Guk Kim (D) Se Hwan Hwang (i) \\ Department of Otolaryngology-Head and Neck Surgery, College of Medicine, The Catholic University of Korea, Seoul, Korea
}

Objectives. Although osteotomy is an important part of rhinoplasty, it is known to be closely related to postoperative eyelid edema and ecchymosis. We aimed to evaluate the effects of periosteal elevation prior to osteotomy on eyelid edema and ecchymosis.

Methods. Two authors reviewed studies in the Medline, Scopus, and Cochrane databases published through May 2019. Randomized controlled trials comparing periosteal elevation (subperiosteal tunneling) with periosteal preservation that reported eyelid edema or ecchymosis or subconjunctival hemorrhage as outcomes of interest were included. From each study, the baseline characteristics of the study subjects, the quality of the study, the number of patients in the treatment and control groups, and outcomes were extracted.

Results. Data for meta-analysis were identified in six studies with a total of 208 patients. Eyelid ecchymosis and edema within 3 days postoperatively were significantly more common in the periosteal elevation group than in the preservation group, although such an association was not found for edema on postoperative day 7 (standardized mean difference [SMD], $0.21 ; 95 \%$ confidence interval $[\mathrm{CI}],-0.09$ to $0.50 ; \mathrm{I}^{2}=0 \%$ ). There was no significant difference in subconjunctival hemorrhage on day 1 (SMD, $0.31 ; 95 \% \mathrm{CI},-0.09$ to $0.72 ; \mathrm{I}^{2}=0 \%$ ).

Conclusion. Periosteal preservation during lateral osteotomy may reduce eyelid edema and ecchymosis compared to periosteal elevation. Further studies with rigorous research methods should be carried out to determine the effectiveness of different techniques in lateral osteotomy.

Keywords. Osteotomy; Periosteum; Edema; Ecchymosis; Systematic Review; Meta-analysis

\section{INTRODUCTION}

Rhinoplasty is considered to be a popular and effective form of cosmetic surgery [1]. Nevertheless, its postoperative complications may include significant eyelid edema and ecchymosis [2]. Periorbital edema may cause difficulties in visual acuity in the early postoperative period, and ecchymosis may increase perior-

\footnotetext{
- Received October 8, 2019

Revised December 20, 2019

Accepted January 2, 2020

- Corresponding author: Se Hwan Hwang

Department of Otolaryngology-Head and Neck Surgery, Bucheon St.

Mary's Hospital, College of Medicine, The Catholic University of Korea,

327 Sosa-ro, Wonmi-gu, Bucheon 14647, Korea

Tel: +82-32-340-7044, Fax: +82-32-340-2674

E-mail: yellobird@catholic.ac.kr
}

bital pigmentation and cause disruptions in the patient's social activities. The main cause of eyelid edema and ecchymosis after rhinoplasty is soft tissue damage at the osteotomy site [2]. Careful and delicate surgical manipulation can help to reduce such damage, but it cannot be completely prevented.

External percutaneous osteotomy and the internal endonasal technique are the two most common approaches used in rhinoplasty. Considering the risk of periosteal injury and the manipulation of the surrounding soft tissue during osteotomy, lateral osteotomy can be done with or without periosteal elevation (subperiosteal tunneling) [3]. However, there is no consensus regarding which osteotomy method is more effective for reducing morbidity in rhinoplasty procedures. Since rhinoplasty remains a challenging procedure to this day, it is important for clinicians to follow the best practices for reducing postoperative complica-

Copyright $\odot 2020$ by Korean Society of Otorhinolaryngology-Head and Neck Surgery.

This is an open-access article distributed under the terms of the Creative Commons Attribution Non-Commercial License (https://creativecommons.org/licenses/by-nc/4.0)

which permits unrestricted non-commercial use, distribution, and reproduction in any medium, provided the original work is properly cited. 
tions. This review aimed to evaluate the efficacy of periosteal elevation. To assess the evidence for periosteal elevation prior to lateral osteotomy, we conducted a review of the literature to identify studies investigating eyelid edema, ecchymosis, and subconjunctival hemorrhage in patients undergoing lateral osteotomy with or without periosteal elevation.

\section{MATERIALS AND METHODS}

\section{Search strategy and selection of studies}

Studies published in English until May 2019 from Medline, Scopus, and Cochrane Register of Controlled Trials were identified. Search terms were "rhinoplasty," "osteotomy," "periosteum," "edema," and "ecchymosis." We also checked the reference lists of identified studies to ensure that relevant studies were not missed.

Two reviewers (JSK, SHH) independently screened all abstracts and titles for candidate studies, excluding those that were not associated with lateral osteotomy of rhinoplasty. Randomized controlled trials that studied patients undergoing rhinoplasty and periosteal elevation or periosteal preservation were included. Studies were excluded from analysis if patients underwent additional surgery (such as blepharoplasty or orthognathic surgery) or if reports were duplicated or if the results were not clearly reported as quantifiable data, or if appropriate data could not be extracted and calculated from published results. Fig. 1 shows the search strategy for meta-analysis.

\section{Data extraction and risk of bias assessment}

Data from included studies were extracted using standardized forms. Primary outcomes were degree of eyelid edema [3-6], ecchymosis [3-8], and subconjunctival hemorrhage [3,4] comparing different osteotomy methods with another methods during the postoperative period (within 3 days or the seventh postoperative day). Eyelid edema and ecchymosis were assessed individually using visual grading scales. On the grading scale, the smallest number indicated no edema or ecchymosis, and the largest number indicated severe edema enough to close the eyelid or severe ecchymosis spreading to the lateral canthus.

\section{HIGHLIIGTTS}

- Eyelid edema within 3 days after rhinoplasty was significantly more common in the periosteal elevation group than in the periosteal preservation group.

- Eyelid ecchymosis was significantly more common in the periosteal elevation group than in the periosteal preservation group, both within 3 days and at 7 days after rhinoplasty.

- Periosteal preservation during osteotomy may reduce eyelid edema and ecchymosis compared to periosteal elevation.

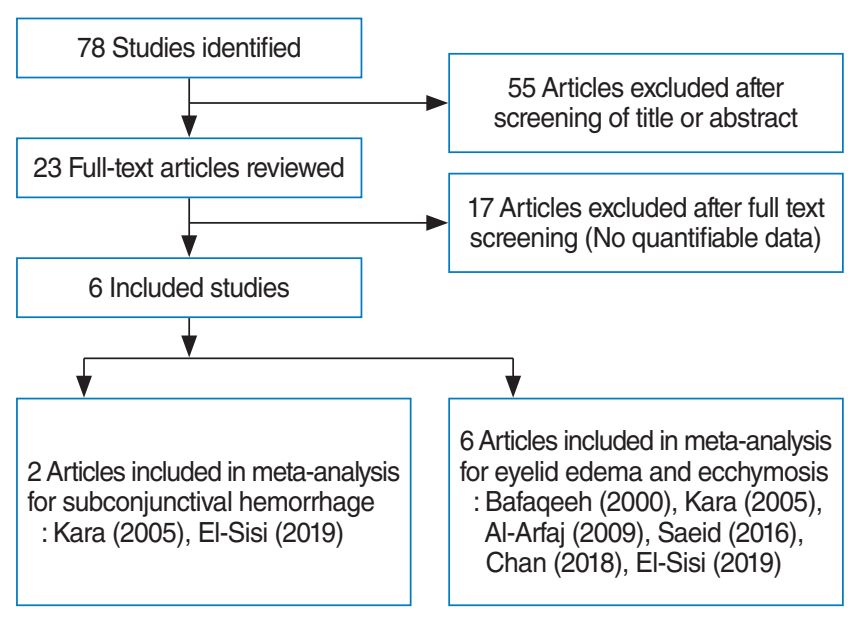

Fig. 1. Diagram of study selection.

In studies of the effect of subperiosteal tunneling on measured outcomes, data on the number of patients, grading scale, and $P$-value were extracted. Quality assessment of the included randomized controlled studies was performed using the Cochrane risk of bias tool. We used a "risk of bias" table including random sequence generation, allocation concealment, blinding, incomplete outcome data, and free of selective reporting (Fig. 2).

\section{Statistical analysis}

A meta-analysis of the selected studies was conducted by R statistical software (R Foundation, Vienna, Austria) with continuous measurements comparing the mean and standard deviation between the control and experimental groups. The effect sizes of edema, ecchymosis, and subconjunctival hemorrhage were expressed as the standardized mean difference (SMD). Heterogeneity was confirmed by Cochran Q statistic test and $\mathrm{I}^{2}$ test. In this analysis, outcomes that did not show heterogeneity $\left(\mathrm{I}^{2}<50\right)$ were analyzed using fixed-effects model.

\section{RESULTS}

Six studies with a total of 208 patients were included in this meta-analysis. Due to the incomplete reporting of patient variables in these studies, a clear comparison of patients' overall characteristics could not be made. The characteristics of the included studies are shown in Table 1.

Eyelid edema (SMD, 0.45; 95\% confidence interval [CI], 0.18 to $0.72 ; \mathrm{I}^{2}=35 \%$ ) within 3 days postoperatively was significantly more common in the periosteal elevation group than in the preservation group. However, edema on postoperative day 7 (SMD, $0.21 ; 95 \% \mathrm{CI},-0.09$ to $0.50 ; \mathrm{I}^{2}=0 \%$ ) showed no significant difference between the two groups (Fig. 3). Eyelid ecchymosis was significantly more common in the periosteal elevation group than in the preservation group (within 3 days postoperatively: SMD, 

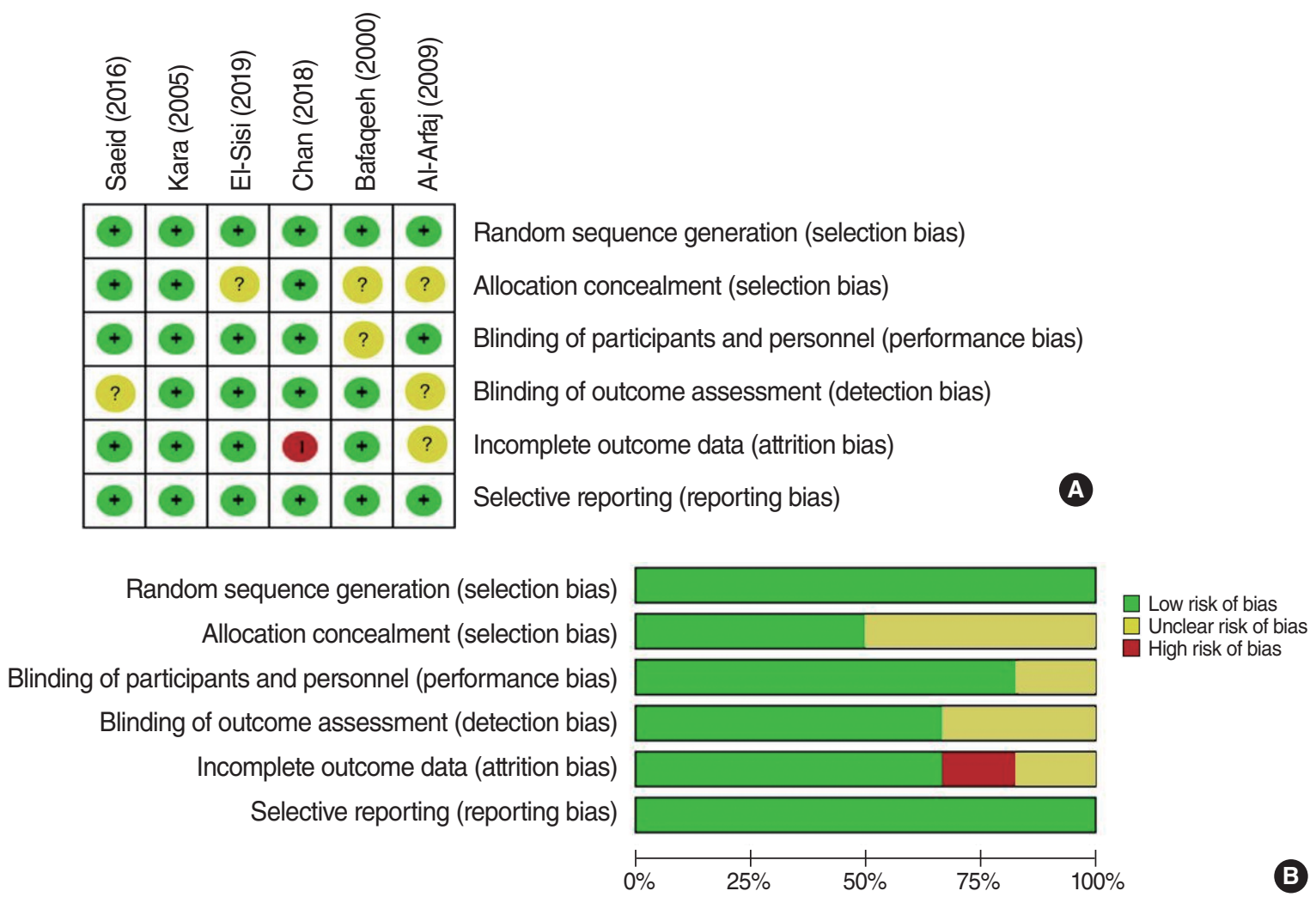

Fig. 2. Risk of bias assessment. (A) Risk of bias summary. (B) Risk of bias graph.

Table 1. Summary of studies included in the meta-analysis

\begin{tabular}{|c|c|c|c|c|c|c|c|c|}
\hline Study & $\begin{array}{l}\text { Sample } \\
\text { size }\end{array}$ & $\begin{array}{c}\text { Number }(\mathrm{M} / \mathrm{F}) \\
\text { age }(\mathrm{yr})\end{array}$ & $\begin{array}{c}\text { Outcome measure } \\
\text { analyzed }\end{array}$ & $\begin{array}{l}\text { Study } \\
\text { type }\end{array}$ & $\begin{array}{c}\text { Pathway of lateral } \\
\text { osteotomy }\end{array}$ & $\begin{array}{l}\text { Surgical instruments of } \\
\text { lateral osteotomy }\end{array}$ & $\begin{array}{l}\text { Other surgical } \\
\text { manipulation }\end{array}$ & Control \\
\hline $\begin{array}{l}\text { Bafaqeeh et al. } \\
\text { (2000) [8] }\end{array}$ & 20 & No description & Eyelid ecchymosis & $\mathrm{RCT}$ & Low-to-high & $\begin{array}{l}\text { 4-mm curved } \\
\text { osteotome }\end{array}$ & $\begin{array}{l}\text { Dorsal } \\
\text { reduction }\end{array}$ & $\begin{array}{c}\text { Contralateral side of } \\
\text { the same patient }\end{array}$ \\
\hline $\begin{array}{l}\text { Kara et al. } \\
(2005)[3]\end{array}$ & 18 & 15/3; $26(18-53)$ & $\begin{array}{l}\text { Eyelid ecchymosis, } \\
\text { eyelid edema, } \\
\text { Subconjunctival } \\
\text { hemorrhage }\end{array}$ & $\mathrm{RCT}$ & No description & $\begin{array}{l}\text { 4-mm curved } \\
\text { osteotome }\end{array}$ & $\begin{array}{l}\text { Dorsal hump } \\
\text { removal }\end{array}$ & $\begin{array}{l}\text { Contralateral side of } \\
\text { the same patient }\end{array}$ \\
\hline $\begin{array}{l}\text { Al-Arfaj et al. } \\
\text { (2009) [7] }\end{array}$ & 78 & No description & Eyelid ecchymosis & $\mathrm{RCT}$ & Low-to-high & $\begin{array}{l}\text { 4-mm curved } \\
\text { osteotome }\end{array}$ & $\begin{array}{l}\text { Dorsal hump } \\
\text { removal }\end{array}$ & $\begin{array}{c}\text { Contralateral side of } \\
\text { the same patient }\end{array}$ \\
\hline $\begin{array}{l}\text { Saeid et al. } \\
\text { (2016) [6] }\end{array}$ & 30 & $9 / 21 ; 20.4 \pm 2.7$ & $\begin{array}{l}\text { Eyelid ecchymosis, } \\
\text { eyelid edema }\end{array}$ & $\mathrm{RCT}$ & No description & $\begin{array}{l}\text { 4-mm curved } \\
\text { osteotome }\end{array}$ & No description & $\begin{array}{c}\text { Contralateral side of } \\
\text { the same patient }\end{array}$ \\
\hline $\begin{array}{l}\text { Chan et al. } \\
(2018)[5]\end{array}$ & 34 & $6 / 28 ; 27.9 \pm 9.2$ & $\begin{array}{l}\text { Eyelid ecchymosis, } \\
\text { eyelid edema }\end{array}$ & $\mathrm{RCT}$ & No description & $\begin{array}{l}\text { 6-mm unguarded } \\
\text { cottle osteotome }\end{array}$ & No description & $\begin{array}{c}\text { Contralateral side of } \\
\text { the same patient }\end{array}$ \\
\hline $\begin{array}{l}\text { El-Sisi et al. } \\
(2019)[4]\end{array}$ & 28 & $19 / 9 ; 23.7 \pm 3.9$ & $\begin{array}{l}\text { Eyelid ecchymosis, } \\
\text { eyelid edema, } \\
\text { subconjunctival } \\
\text { hemorrhage }\end{array}$ & $\mathrm{RCT}$ & High-to-low & 2-mm osteotome & $\begin{array}{l}\text { Hump } \\
\text { resection }\end{array}$ & $\begin{array}{c}\text { Contralateral side of } \\
\text { the same patient }\end{array}$ \\
\hline
\end{tabular}

Values are presented as mean (range) or mean \pm standard deviation.

$\mathrm{M}$, male; F, female; RCT, randomized controlled trial.

0.48 ; $95 \%$ CI, 0.28 to $0.68 ; \mathrm{I}^{2}=0 \%$; on postoperative day 7 : SMD, $0.36 ; 95 \%$ CI, 0.07 to $0.65 ; \mathrm{I}^{2}=0 \%$ ) (Fig. 4). There was no significant difference in subconjunctival hemorrhage on day 1 (SMD, $0.31 ; 95 \%$ CI, -0.09 to $0.72 ; \mathrm{I}^{2}=0 \%$ ) (Fig. 5). No significant inter-study heterogeneity was found for these outcomes $\left(\mathrm{I}^{2}<50 \%\right)$.

\section{DISCUSSION}

Repositioning or changing the location of the nasal bone is essential in most rhinoplasty procedures performed for external correction [9]. In particular, medial movement of the nasal bone via osteotomy allows the pyramid to be reconstructed to its nor- 


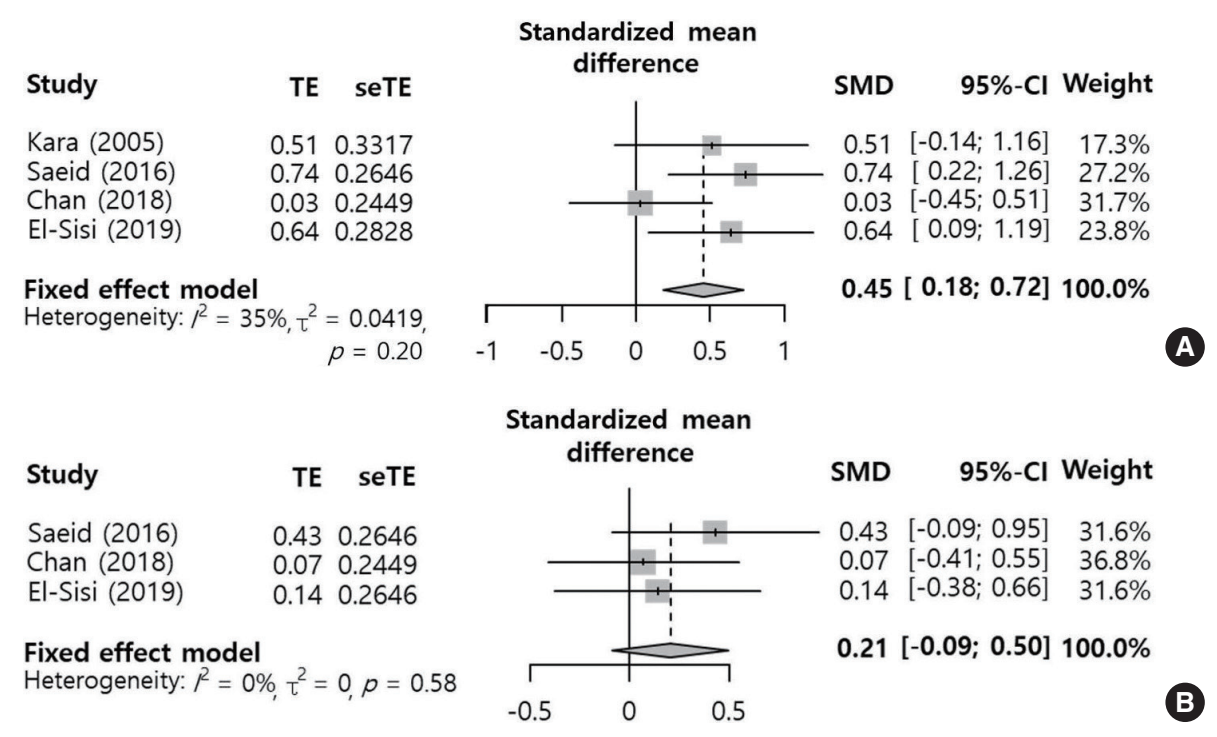

Fig. 3. Periosteal elevation versus periosteal preservation: standard mean difference of eyelid edema within 3 days postoperatively (A) and on postoperative day 7 (B). TE, treatment effect; seTE, standard error of treatment effect; SMD, standardized mean difference; CI, confidence interval.

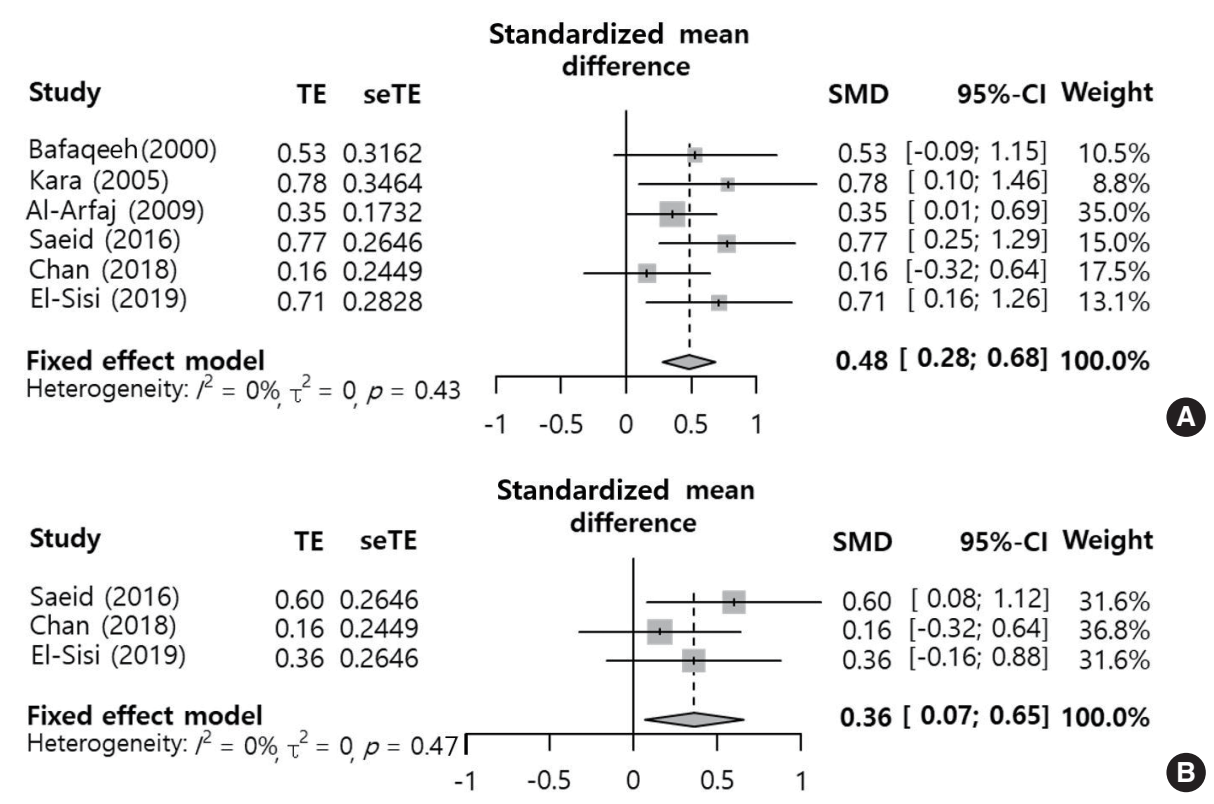

Fig. 4. Periosteal elevation versus periosteal preservation: standard mean difference of eyelid ecchymosis within 3 days postoperatively (A) and on postoperative day 7 (B). TE, treatment effect; seTE, standard error of treatment effect; SMD, standardized mean difference; Cl, confidence interval.

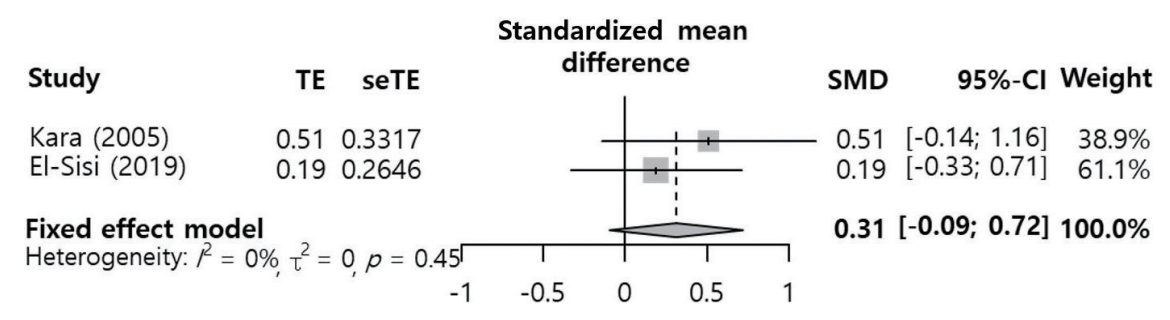

Fig. 5. Periosteal elevation versus periosteal preservation: standard mean difference of subconjunctival hemorrhage on day 1 postoperatively. TE, treatment effect; seTE, standard error of treatment effect; SMD, standardized mean difference; Cl, confidence interval. 
mal condition [10]. Osteotomy is performed with the goals of straightening a deviated dorsum, narrowing the nasal dorsum, and opening the nasal vault [11]. Eyelid edema and ecchymosis, which are the most common postoperative complications of osteotomy, can be caused by damage to arteries or veins and soft tissue injuries during lateral osteotomy [5]. In lateral osteotomy, considerable force is delivered to the soft tissues and bones to mobilize the nasal bone. Thus, lateral osteotomy should be performed safely and accurately with minimal postoperative complications while producing aesthetically satisfactory results $[12,13]$. In order to minimize the complications of lateral osteotomy, various innovations have been made in surgical instruments, preoperative local infiltration, and intraoperative techniques $[7,14,15]$.

Lateral osteotomy can be performed after periosteal elevation. A subperiosteal tunnel is formed by elevating the periosteum and upper layer from the bony cortex in the path of the osteotomy [5]. The goal of subperiosteal tunneling is to protect the blood vessels and to reduce periosteal injury during osteotomy [16]. This technique uses an elevator to make the subperiosteal tunnel wide enough for the osteotome to enter. This prevents the osteotome from damaging the soft tissue, resulting in a bloodless osteotomy $[15,17,18]$. The elevated periosteum also becomes a barrier that prevents blood from spreading into subcutaneous tissues [16]. However, several studies have suggested that periosteal elevation is more likely to cause damage to vessels $[3,4,7]$. In addition, subperiosteal tunneling can damage the lacrimal sac and the canthal ligament because the medial canthal ligament is just above the lacrimal sac $[10,12]$. Therefore, elevation of the periosteum may be unsafe because it can damage surrounding structures.

Edema and ecchymosis have been reported to reach maximum severity within 3 days postoperatively although they may persist until the 9th postoperative day [19]. Therefore, we used two time points to investigate changes in these outcomes over time. Periosteal elevation was found to be associated with more frequent edema and ecchymosis (postoperative edema within 3 days and postoperative ecchymosis at both time points), except for eyelid edema on postoperative day 7 . In particular, the SMDs of the edema and ecchymosis outcomes within 3 days after surgery were near 0.5 , with clinically medium effect sizes [20]. Because periosteal elevation requires more manipulation of the tissue, it may increase the risk of periorbital edema and ecchymosis [3]. Subperiosteal tunnels can also serve as a potential space for blood to accumulate and spread into the surrounding tissue [3,7]. Although periosteal elevation is designed to protect blood vessels, it can simultaneously provide a space for hematoma to spread more widely. Some studies have suggested that complications may be more frequent if the stabilization and functioning of the periosteum are completely stopped by elevation, rather than partial damage [21,22]. These possible explanations provide support for our results on postoperative edema and ecchymosis.

Periorbital ecchymosis is not limited to the subcutaneous tissue of the eyelids; instead, it sometimes continues through the orbital adipose tissue, resulting in subconjunctival ecchymosis [23]. Considering the positive effect of periosteal preservation on eyelid edema and ecchymosis, subconjunctival ecchymosis would be expected to be significantly less frequent in the periosteal preservation group than in the periosteal elevation group. In contrast to our expectations, postoperative ecchymosis on day 1 showed no significant difference between the two groups. However, this result was only based on two studies. Thus, the clinical implications of this result may not be meaningful, which is a limitation of our findings.

A limitation of our study is that surgical manipulations other than subperiosteal tunneling might also increase postoperative complications. In addition, when blood accumulates in surrounding tissues as a result of extensive bleeding during surgery, periorbital ecchymosis may be more likely. The results of our analysis could not distinguish these factors affecting complications that are distinct from subperiosteal tunneling. Nonetheless, in each of the studies that we included, there was no difference in the management of the two groups, enabling a meaningful comparison of the outcome measures. We considered that using the SMD to compare two groups under the same conditions was adequate from a methodological perspective. The spread of edema or bleeding could also vary depending on individual-level variations in skin thickness and the amount of subcutaneous fat $[4,24]$. If further studies are conducted on this issue, it may be possible to obtain more reliable results.

\section{CONFLICT OF INTEREST}

No potential conflict of interest relevant to this article was reported.

\section{ACKNOWLEDGMENTS}

This research was supported by Basic Science Research Program through the National Research Foundation of Korea (NRF) funded by the Ministry of Education (2018R1D1A1B07045421). The statistical consultation was supported by the Department of Biostatistics of the Catholic Research Coordinating Center.

\section{ORCID}

$\begin{array}{ll}\text { Ji-Sun Kim } & \text { https://orcid.org/0000-0003-4783-4654 } \\ \text { Sun Hong Kim } & \text { https://orcid.org/0000-0001-8736-7558 } \\ \text { Hyesook Lee } & \text { https://orcid.org/0000-0002-5903-696X } \\ \text { Byung Guk Kim } & \text { https://orcid.org/0000-0003-2794-7803 }\end{array}$ 
Se Hwan Hwang https://orcid.org/0000-0002-2838-7820

\section{AUTHOR CONTRIBUTIONS}

Conceptualization: SHH. Data curation: all authors. Formal analysis: SHH. Funding acquisition: SHH. Methodology: SHH. Project administration: all authors. Visualization, Writing-original draft, review \& editing: SHH, JSK.

\section{REFERENCES}

1. Saedi B, Sadeghi M, Fekri K. Comparison of the effect of corticosteroid therapy and decongestant on reducing rhinoplasty edema. Am J Rhinol Allergy. 2011 Jul-Aug;25(4):e141-4.

2. Koc S, Gurbuzler L, Yaman H, Eyibilen A, Suren M, Kaya Z, et al.The effectiveness of steroids for edema, ecchymosis, and intraoperative bleeding in rhinoplasty. Am J Rhinol Allergy. 2011 Mar-Apr;25(2): e95-8.

3. Kara CO, Kara IG, Topuz B. Does creating a subperiosteal tunnel influence the periorbital edema and ecchymosis in rhinoplasty? J Oral Maxillofac Surg. 2005 Aug;63(8):1088-90.

4. El-Sisi H,Abdelwahab M, Most SP. Association of periosteal sweeping vs periosteal preservation with early periorbital sequelae among patients undergoing external perforating osteotomy during rhinoplasty. JAMA Facial Plast Surg. 2019 May;21(3):185-90.

5. Chan DS, Roskies M, Jooya AA, Samaha M. Postoperative ecchymosis and edema after creation of subperiosteal tunnels in rhinoplasty: a randomized clinical trial. JAMA Facial Plast Surg. 2019 Mar;21(2): 133-6.

6. Saeid A, Mojtaba M, Sedighe V, Nasim B, Mohammad M. Effect of lateral osteotomy in subperiostal plan in reducing severity of periorbital edema and ecchymosis after rhinoplasty. Br J Med Res. 2016 May;15(6):1-5.

7. Al-Arfaj A,Al-Qattan M,Al-Harethy S, Al-Zahrani K. Effect of periosteum elevation on periorbital ecchymosis in rhinoplasty. J Plast Reconstr Aesthet Surg. 2009 Nov;62(11):e538-9.

8. Bafaqeeh SA. Lateral nasal osteotomies: does the creation of a periosteal tunnel influence the degree of postoperative ecchymosis? Can J Plast Surg. 2000 Apr;8(3):101-2.

9. Cakr B, Finocchi V, Tambasco D, Oreroglu AR, Dogan T. Osteoecto- my in rhinoplasty: a new concept in nasal bones repositioning. Ann Plast Surg. 2016 Jun;76(6):622-8.

10. Giacomarra V, Russolo M, Arnez ZM, Tirelli G. External osteotomy in rhinoplasty. Laryngoscope. 2001 Mar;111(3):433-8.

11. Newberry CI, Mobley S. Correction of the crooked nose. Facial Plast Surg. 2018 Oct;34(5):488-96.

12. Thomas JR, Griner NR, Remmler DJ. Steps for a safer method of osteotomies in rhinoplasty. Laryngoscope. 1987 Jun;97(6):746-7.

13. ReesTD. Nasal osteotomies: a clinical comparison of the perforating methods versus the continuous technique. Plast Reconstr Surg. 2005 May;115(6):1783-4.

14. Tirelli G,Tofanelli M, Bullo F, Bianchi M, Robiony M. External osteotomy in rhinoplasty: Piezosurgery vs osteotome. Am J Otolaryngol. 2015 Sep-Oct;36(5):666-71.

15. Tardy ME, Denneny JC. Micro-osteotomies in rhinoplasty: a technical refinement. Facial Plast Surg. 1984 Jan;1(2):137-45.

16. Ong AA, Farhood Z, Kyle AR, Patel KG. Interventions to decrease postoperative edema and ecchymosis after rhinoplasty: a systematic review of the literature. Plast Reconstr Surg. 2016 May;137(5):144862.

17. Sinha V, Gupta D, More Y, Prajapati B, Kedia BK, Singh SN. External vs. internal osteotomy in rhinoplasty. Indian J Otolaryngol Head Neck Surg. 2007 Mar;59(1):9-12.

18. Rohrich RJ, Krueger JK, AdamsWP Jr, Hollier LH Jr.Achieving consistency in the lateral nasal osteotomy during rhinoplasty: an external perforated technique. Plast Reconstr Surg. 2001 Dec;108(7): 2122-30.

19. Ilhan AE, Cengiz B, Caypinar Eser B. Double-blind comparison of ultrasonic and conventional osteotomy in terms of early postoperative edema and ecchymosis. Aesthet Surg J. 2016 Apr;36(4):390-401.

20. Acion L, Peterson JJ,Temple S, Arndt S. Probabilistic index: an intuitive non-parametric approach to measuring the size of treatment effects. Stat Med. 2006 Feb;25(4):591-602.

21. Goldfarb M, Gallups JM, Gerwin JM. Perforating osteotomies in rhinoplasty. Arch Otolaryngol Head Neck Surg. 1993 Jun;119(6): 624-7.

22. Rohrich RJ, Minoli JJ, Adams WP, Hollier LH.The lateral nasal osteotomy in rhinoplasty: an anatomic endoscopic comparison of the external versus the internal approach. Plast Reconstr Surg. 1997 Apr; 99(5):1309-12.

23. Kara CO, Kara IG, Yaylali V. Subconjunctival ecchymosis due to rhinoplasty. Rhinology. 2001 Sep;39(3):166-8.

24. Hashemi M, Mokhtarinejad F, Omrani M. A comparison between external versus internal lateral osteotomy in rhinoplasty. J Res Med Sci. 2005 Jan;10(1):10-5. 